\title{
Key information systems management issues: A comparative study in South Africa
}

\author{
M.L. Hart*, S. Berkowitz, J. Ryan and K. Waspe \\ Department of Information Systems, University of Cape Town, \\ Private Bag, Rondebosch 7701, Republic of South Africa \\ mhart@commerce.uct.ac.za
}

Received June 2004

\begin{abstract}
The identification of key Information Systems (IS) management issues is important for all players in the industry. Most academic research has followed the form of the Society for Information Management (SIM) studies, originating in the early 1980's in the United States of America (USA), and since replicated in many countries, yet no comprehensive recent study had been carried out in South Africa. This study was performed within weeks of September 11, 2001 on a sample of 121 members of the Cape IT Initiative (CITI), and of the Computer Society of South Africa (CSSA), from a range of industries and geographical regions. Highest rated issues were business intelligence, a responsive IT infrastructure and disaster recovery, while Business Relationship and Technical Infrastructure issues were prominent overall. Demographic factors did not significantly influence overall results. Rankings were correlated with an earlier South African study and with 1997 Australian research, but not with a 1995 USA study. The economic developmental status of a country was found to be linked to the key issues that country faces.
\end{abstract}

The authors would like to thank CITI and the CSSA for their assistance with the survey, and the referees for their useful comments.

*To whom all correspondence should be addressed.

\section{Introduction}

Understanding the needs of the business and dealing with management issues in Information Systems is critical to any modern day business success. Academic institutions also need to keep abreast of what is occurring in the Information Systems industry so that graduates are appropriately skilled. This demand for information from both academia and industry creates a need to investigate the current key IS management issues (Brancheau, Janz \& Wetherbe, 1996).

Key issues studies began in the USA over twenty years ago (Ball \& Harris, 1982; Dickson, Leitheiser, Nechis \& Wetherbe, 1984). Niederman, Brancheau and Wetherbe (1991) proposed a categorisation model of issues that would assist comparison between studies across both time and region. Authors using this format in later studies include Brancheau et al. (1996) in the USA, and Chou and Jou (1999), Dekleva and Zupancic (1996) and Gottschalk, Watson and Christensen (2000) in other countries.

This paper starts by examining literature on the subject, then describes the research methodology and objectives of new research into this area. Having identified key Information Systems management issues currently prevalent in South Africa, relationships to some previous studies are investigated, and factors that may affect the ranking of issues are examined. The classification model used to compare different studies is analysed to assess whether it suitably categorises issues. Finally conclusions are drawn and are used to make recommendations to both academia and industry.

\section{Literature review}

The widespread use of computerised information systems in business in the latter half of the $20^{\text {th }}$ century increased the concerns of executives managing these resources. According to Remenyi, Lubbe, Meiring and Smith (1999), organisations that interact with information systems will experience some or all of the same fundamental issues. The use of studies into key IS management issues enables professional societies, IS vendors, consultants, educators and researchers to serve their respective markets better (Brancheau et al., 1996; Mata \& Fuerst, 1997; Rockart, Earl \& Ross, 1996). The pace at which information systems change is also indicative of why regular studies should be performed (Gottschalk et al., 2000; Pervan, 1998; Remenyi et al., 1999; Rockart et al., 1996). Organisations that make use of information systems should use the studies to become more responsive and flexible, two of the key business drivers of the 1990's identified by Brancheau et al. (1996).

Mata and Fuerst (1997) and Remenyi and Whittaker (1995) suggest that benchmarking against other firms in the industry may not provide a competitive advantage, but may avoid losing one. Educational institutions can emphasise locale-specific topics in the courses they offer (Mata \& Fuerst, 1997; Hart, 2000). Academics may also use the issues uncovered as a basis for further research. 


\section{Factors that may affect the research}

To better analyse results of these studies within a global context, the interpretation of the various studies should take into account factors that contribute to regional differences (Watson, Kelly, Galliers \& Brancheau, 1997). As Gibson, Donnelly and Ivancevich (2000) mention, managers are forced to make decisions based on economic criteria. The political situation of a country (Watson et al., 1997) also influences the way business is conducted. These influences are especially prevalent in South Africa, as the legacy of Apartheid and globalisation has affected the structure of industries and the economy (SAITIS, 2000). Aspects pertaining to South Africa investigated by Hodge and Miller (1997) include the following:

\section{National Culture:}

Differences in national culture between South African and other countries might affect interpretation of the data (Watson et al., 1997).

\section{Economic Structure:}

During the decade prior to the study the local currency (Rand) depreciated considerably against most other currencies. The attraction of earning foreign currency, the legacy of Apartheid and the transportability of IS skills contributed to a shrinking pool of IS employees. The weaker Rand at the time led to a high cost of imported technology, and higher market entry costs (Remenyi \& Whittaker, 1995). The disparity in income within the economy reinforced the lack of technology access to those in lower income brackets (SAITIS, 2000). Palvia, Palvia and Zigli (1992) note that key IS management issues change as a nation progresses through different stages of economic development.

\section{Political and Legal Issues:}

The regulatory structure within South Africa, including labour law and employment equity policies, may affect results when compared to a less-regulated free market economy (SAITIS, 2000). Prioritisation of IS issues by government, and a focus of government on eCommerce, might influence managers to concentrate on areas of business where government provides funding or subsidies (Ein-Dor, Myers \& Raman, 1997; SAITIS, 2000).

\section{Technological Status:}

Economic conditions such as the monopoly held by Telkom in South Africa affect the cost structure of the industry, and investment decisions (Remenyi \& Whittaker, 1995). Absence of certain technologies may affect the ranking of key issues, as in Estonia where Internet access was scarce (Watson et al., 1997).

\section{Society for Information Management (SIM) Studies}

Since 1980 surveys of key IS management issues have been conducted on members of the Society for Information Management (SIM). The standard nature of these surveys provides a good basis for comparison over time and between regions (Hart, 2000; Pervan, 1998; Watson et al., 1997), and they have been replicated many times in a range of countries. Most studies conducted a preliminary analysis of the key issues in previous studies, and synthesised these with current issues selected from literature or through a first round of responses. This allows for more continuity and comparability between studies (Niederman et al., 1991).

Once this process is complete, managers and executives are asked to rate each issue on a scale of one to ten (Gottschalk, 1998). Some SIM studies have also incorporated the Delphi approach, utilising multiple rounds of surveys to achieve consensus. In order to facilitate analysis, several authors have categorised various issues together (Pervan, 1998). Niederman et al. (1991) developed a broad classification scheme that grouped together all issues under the following categories (Gottschalk et al., 2000).

\section{Business Relationship Issues (BR):}

These deal with concerns external to the IS department, primarily with management of the relationship between IS and the broader business.

Technological Infrastructure Issues (TI):

These focus on technology concerns, mainly the integration of technology in supporting basic business needs.

Internal Effectiveness Issues (IE):

These are concerned with essential activities that comprise the bulk of the IS function's work.

Technological Application Issues (TA):

These issues centre on the business application of specific information technologies.

The use of the classification scheme facilitates comparison of information over time, while preventing distortion by certain issues that may prevail for a very short period of time (Watson et al., 1997). The number of top ten issues, top twenty issues, or the top ranking, in each of the categories provides an indication of their relative importance (Hart, 2000; Palvia, Palvia \& Whitworth, 2002).

\section{Limitations of SIM studies}

The number of responses received in some SIM studies has been relatively low, possibly limiting representivity and power of statistical tests. Value may be reduced because of time taken to analyse and publish the research (Gottschalk, 1998). Cultural bias may exist within the questionnaire if language or concepts foreign to the region are used. Gottschalk (1998) mentions four potential problems: consensus versus aggregation, interaction between issues, lack of theoretical backing for changes and additions, and lack of differentiation between highest and lowest ranked issues. The focal area of the SIM research was the USA, which can reduce comparability across other regions (Gottschalk et al., 2000). Watson et al. (1997) note that development and use of a framework applicable for comparison across studies runs the risk of the categorisation becoming too abstract, reducing relevance and meaning to IS management. 


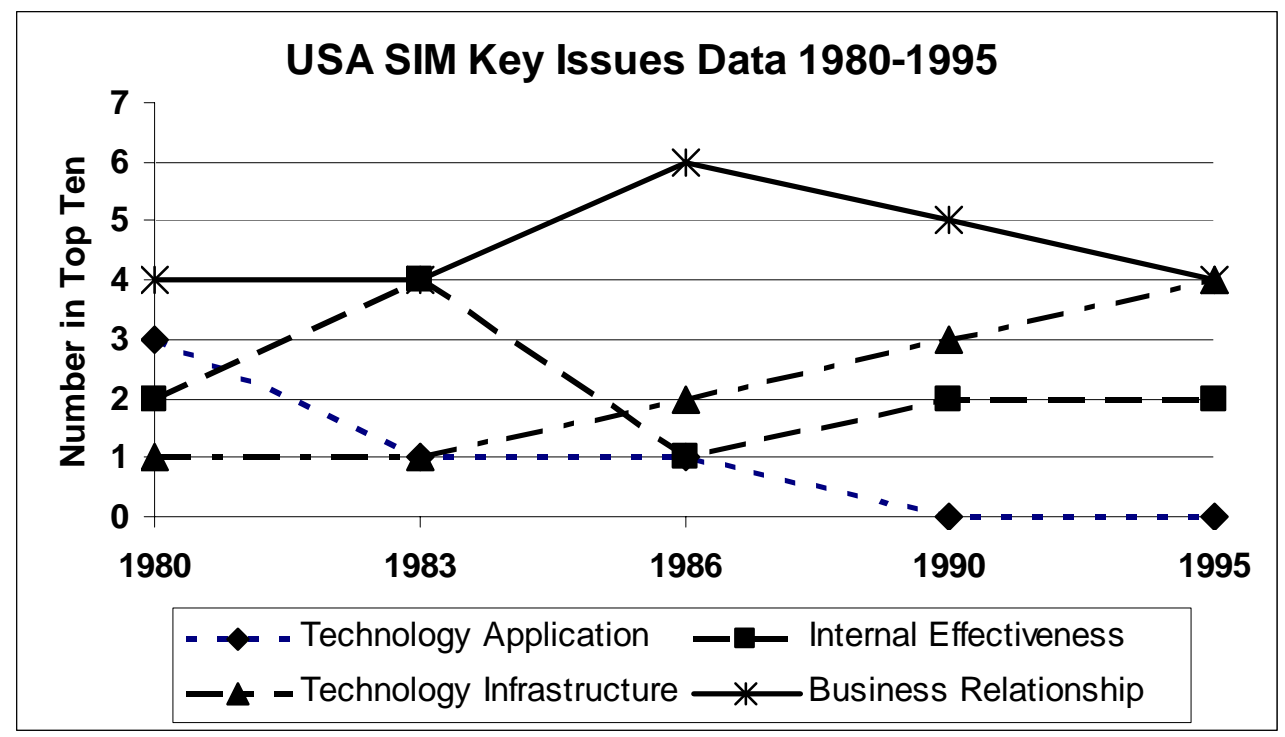

Figure 1: Changes in USA SIM categories 1980 - 1995 (Hart, 2000)

\section{Analysis of USA SIM results from 1980 to 1995}

Figure 1 shows how the number of each category in the top ten issues has changed from 1980 to 1995. Results of the 1980's tended to focus on business relationship (BR) issues. The slight decline in importance of this category with the rise in technology infrastructure (TI) issues led Brancheau et al. (1996) to conclude that the focus had shifted from planning and alignment to implementation and delivery. In order to maintain a responsive TI, the IS department has to be able to change quickly in response to business issues (Brancheau et al., 1996). They consider that the top-ranked 1995 issue, building a responsive IT infrastructure, will be a long-term endeavour.

\section{Previous South African (SA) Studies}

Two studies in line with the SIM format have been performed in South Africa, by Picton (1989) and Hall, Hartley, Mkhasibe and Hart (1999). The small and possibly unrepresentative sample in 1999 made it difficult to draw strong conclusions on South African-specific issues (Hall et al., 1999). Major focus areas in both 1989 and 1999 reflected the importance of aligning IT with corporate strategy and planning. Using IT for competitive advantage, security and control, recruiting IS staff and making effective use of data also featured strongly in both studies.

\section{Justification for further research}

As these two previous SA studies either suffered from age or a small sample size, it was important to update them. For example, with the development and changes in eCommerce, it is likely that later results will differ from the 1999 study, and the two areas of Business to Business (BtoB) and Business to Consumer (BtoC) eCommerce were not separately identified in 1999. Watson et al. (1997: 92) state: 'By assessing the similarities and differences of regional issues, IS executives should be better prepared to manage their increasingly global function.' These studies can be considered a strategic insight into the allocation of resources and time by IS managers for the next 3 to 5 years. Remenyi et al. (1999:1) note that it is important not to waste the large sums invested in IT by organisations, and that it is difficult to manage an IS department successfully unless these key issues are identified and understood. Finally, South Africa and the world have been significantly affected by the events of September 11, 2001 and by recent developments on corporate governance, security and control, such as the local ECT Act of 2002.

\section{Research objectives}

Following the literature study, the following problem statement was chosen for investigation:

"What do South African IS managers consider to be the most important IS management issues over the next three to five years?"

Related objectives are:

1. To identify the key IS management issues prevalent in South Africa.

2. To determine any correlation or trends between the SA results in 1999 and 2001.

3. To test for any correlation between current SA results and those found in the USA (1995) and Australia (1997). The latter country (Pervan, 1998) was chosen as its IS management trends might be expected to precede those in SA slightly.

4. To identify whether demographics (employment position, company location, industry type, organisational size, and the organisation's geographical reach) are associated with the category split of key IS management issues.

5. To identify whether the rating of issues is associated with the country's economic status. 
6. To determine whether the classification model used could be improved upon in the South African context.

\section{Research methodology}

As far as possible the methodology emulated the SIM studies, in order to provide for past and future comparison. In the SIM research, questionnaires were distributed to members of the Society for Information Management, generally senior IS managers and executives, but sometimes also to general managers and CEOs. Niederman et al. (1991: 474) point out that 'the results cannot be claimed to be representative of IS managers in general, but the selected survey population is quite likely to be more perceptive of current trends than samples drawn from most other groups'. In 2001 the process shown in Figure 2 was followed (adapted from Gottschalk et al., 2000).

\section{Sampling frame}

There is currently no comprehensive association of IS managers in South Africa, and finding an accessible and representative sample is challenging. The sampling frame initially chosen for this study was an e-mail list obtained from CITI (Cape Information Technology Initiative). CITI is a non-profit organisation with membership from some of the largest companies in South Africa, as well as smaller entrepreneurial IT companies. Although its focus is mainly on the Western Cape, its members are distributed across South Africa. An online version of the questionnaire was hosted by the University of Cape Town, with the URL:

http://www.commerce.uct.ac.za/informationsystems/resourc es/asp. The Computer Society of South Africa (CSSA) later provided a direct hyperlink to this from their home page, with details of the study placed in prime position on their site (http://www.cssa.org.za/).

\section{Questionnaire Design}

The list of issues was based on the most relevant ones from the local 1999 study, combined with the most recent research done in the USA. Added to this were issues from other reputable non-academic studies such as the PricewaterhouseCoopers (2001) Barometer study, and the IDC World study (2001). This followed the approach of Gottschalk et al., (2000) for their Norwegian study. The preliminary questionnaire followed as closely as possible the well validated format of all past SIM studies, and was piloted with a number of IS consultants, IS academics and IS managers/CIOs. Slight adjustments were than made to ensure applicability and clarity for SA respondents. The final list of issues totalled twenty-eight, distributed unevenly across the four categories BR, IE, TA and TI of Niederman et al. (1991). As in recent SIM studies, a brief summary was given with each issue, and respondents were asked to rate them on a scale of one to ten, where one was unimportant and ten was very important. In the online version the respondent was presented with a drop down list box with the numbers one to ten. At the end of both questionnaire formats was a space for respondents to provide other issues not listed, and any additional comments. The full list of issues is shown in Table 2.

This website consisted of three web pages. An introduction page gave a brief history of key issues research, and discussed the objectives and contact details of the research group. A respondent's details page asked for contact and demographic information. To enforce consistency and make analysis easier, most options were chosen from a list. The actual questionnaire commenced on the third page. Controls ensured that verifiable contact details and demographic information were obtained from everyone completing the questionnaire. Validation of users' IP addresses was performed to prevent respondents entering multiple questionnaires.

\section{Data collection}

The first set of 280 e-mails sent from a random list provided by CITI yielded a low response rate and 65 'address unknown' returns. A further sample from the CITI list confirmed that details of its mobile population were fairly out of date, and analysis revealed that it was not as large or representative of IS Management as initially thought. It was decided, in line with Brancheau and Wetherbe (1987) and others, that general management and IT consultants would be retained in the sample, as their CITI membership implied some understanding of IS issues. Any significant differences in their rankings and those of IS managers would later be assessed via Objective 4. Towards the end of the study the CSSA provided a link to their homepage (rather than use of a membership list, which would also not have been very up-to-date or focussed on IS managers). This link improved overall response and regional representivity.

The total number of responses received was 128 , which was reduced to 121 after removal of invalid replies. Taking only the CITI emails into account the response rate was $19,6 \%$; inclusion of CSSA members who might have seen the link may effectively reduce this to $15 \%$ or slightly lower. Low response rates are not unusual when dealing with a very busy population such as IS managers and executives. Nonresponse bias is however a risk, and the possible effect of this was examined by analysing the results of three 'waves' of respondents. The 121 valid replies were divided into the first 41 received, the next 40, and the final 40 . Across the three groups the overall rankings of each question, and the average scores for each question were compared. Spearman rank correlations were: 0,8466 (Waves 1 and 2), 0,8934 (Waves 2 and 3) and 0,8269 (Waves 1 and 3), all significant at $\mathrm{p}<0,000001$. A multivariate Wilks test across all questions produced a pvalue of 0,1204 , and Kruskal-Wallis ANOVA tests on 25 of the 28 questions gave no significant differences in average scores or in multiple comparisons. Of the three questions with significant differences per wave, only one (making effective use of the data resource) came from the top ten issues. 


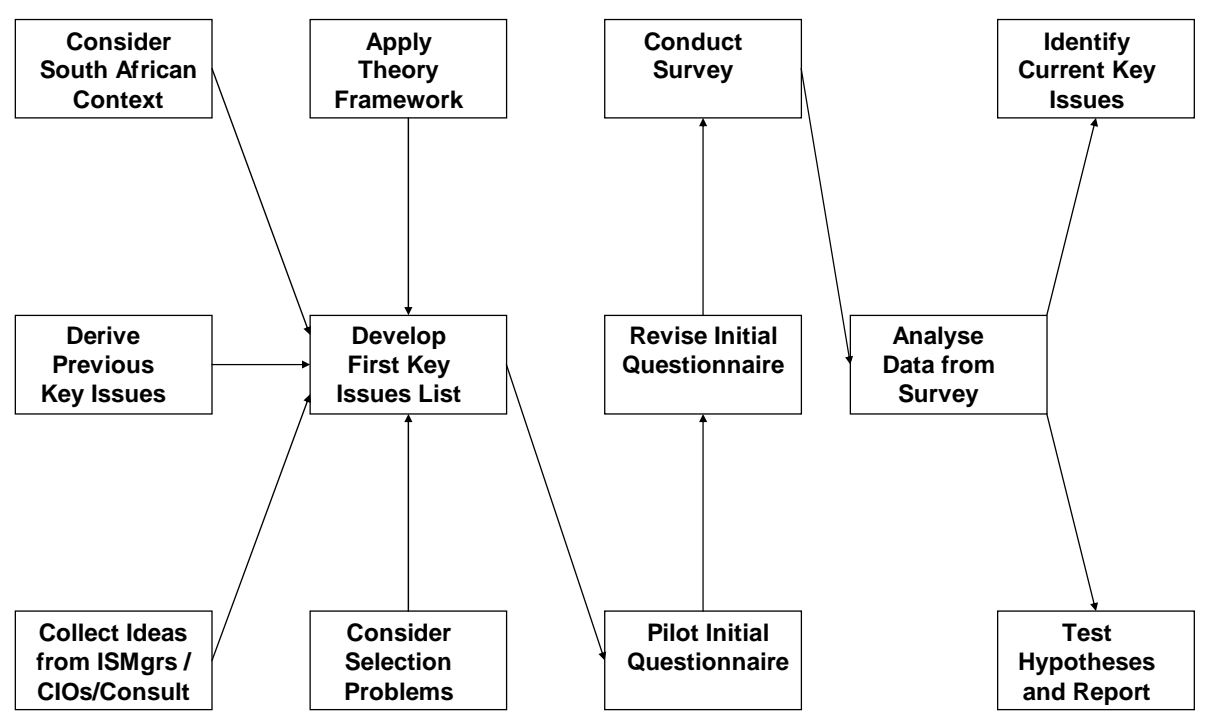

Figure 2: Research Method Followed (adapted from Gottschalk et al., 2000)

Data was protected with network and SQL database passwords, and questionnaire design restricted the choices of the user to the maximum and minimum values for each question. Calculations were performed in Excel 2002 to establish demographic and other information, and Statistica v6,0 was used for relevant statistical tests. The results and commentary are shown in the following sections.

\section{Sampling demographics}

Table 1 shows some sampling demographics of the test sample. The disproportionate number of respondents from the Western Cape can be attributed to the nature of the CITI mailing list. Respondents were distributed across a variety of business sectors, with the biggest group from the services industry. This, and the number of IT consultants, can be attributed to the CITI composition. The entrepreneurial focus of the organisation also explained the number of smaller companies. As discussed previously, a number of senior business managers are also included due to their links to the IT industry. The possible impact of any disproportional sample representation is examined later under Objective 4. It should however generally be noted that caution should be applied in generalising these results to South Africa as a whole due to the strong Western Cape representation.

\section{Analysis of objectives:}

Objective 1. To identify key IS management issues in South Africa

Table 2 lists the summary results of the South African 2001 Key Information Systems Management Issues study. The difference between the $1^{\text {st }}$ and $10^{\text {th }}$ mean is only 0.59 and the average standard deviation and standard error are 2,12 and 0,19 respectively. Pervan (1998) emphasises the need to use caution when analysing the rankings. The fact that issues appear in the top ten, rather than their actual ranking is of importance. There is also a relatively large difference $(0,22)$ between the tenth and the eleventh places.

As can be seen, the majority of the top ten issues are from the Business Relationship category, Because of the closeness of the mean scores it is important to analyse which categories (BR, TI, TA, IE) are included in the top ten as well as in the final list of issues, Palvia et al. (2002) comment on the potential distortion in ranking by counting top ten issues, and provide another method of classification, Two methods were employed to analyse the data: a mean inverted ranking, used for all twenty-eight issues; and the weighted average approach, which was used for the top ten issues, A comparison of the two methods is shown in Table 3.

The mean inverted ranking was determined by assigning the inverse ranking to a particular issue, for example Decision and Executive support was ranked 28 and Customer Relationship Management 18. The mean score for each category was then calculated. The weighted average was calculated by counting the occurrences of a category within the top ten. This was then divided by the total number of issues within this category, e.g. BR had 6 in the top ten and 8 in total, thus it equalled 75\% (6/8). These methods give an indication of the importance of a particular category, while excluding the potential effects of an uneven distribution of issues across categories. 
Table 1: Sampling demographics

\begin{tabular}{c|c|c}
\hline Location & No & Percentage \\
\hline Western Cape & 78 & $64,46 \%$ \\
\hline Gauteng & 34 & $28,10 \%$ \\
\hline KwaZulu-Natal & 6 & $4,96 \%$ \\
\hline Other & 3 & $2,48 \%$ \\
\hline Total & 121 & $100,00 \%$ \\
\hline \multicolumn{2}{|c}{}
\end{tabular}

Organisation Reach

\begin{tabular}{|c|c|c|}
\hline International & 46 & $38,02 \%$ \\
\hline National & 44 & $36,36 \%$ \\
\hline Regional & 31 & $25,62 \%$ \\
\hline & & $100,00 \%$ \\
\hline \multicolumn{3}{|c|}{ Organisation Sector } \\
\hline Services & 51 & $42,15 \%$ \\
\hline Financial & 18 & $14,88 \%$ \\
\hline Manufacturing & 8 & $6,61 \%$ \\
\hline Retail & 5 & $4,13 \%$ \\
\hline Government & 4 & $3,31 \%$ \\
\hline Other & 35 & $28,93 \%$ \\
\hline & & $100,00 \%$ \\
\hline
\end{tabular}

Position

\begin{tabular}{c|c|c}
\hline Senior IS Executive (CIO/VP) & 33 & $27,27 \%$ \\
\hline Other (largely upper mgmt) & 32 & $26,45 \%$ \\
\hline IT Consultant & 29 & $23,97 \%$ \\
\hline IS Department Manager & 14 & $11,57 \%$ \\
\hline IS Section / Functional Mgr & 13 & $10,74 \%$ \\
\hline \multicolumn{2}{|l}{} & $100,00 \%$ \\
\cline { 2 - 3 }
\end{tabular}

Employees in Company

\begin{tabular}{c|c|c}
\hline$<100$ & 60 & $49,59 \%$ \\
\hline $101-1000$ & 34 & $28,10 \%$ \\
\hline $1001-10000$ & 18 & $14,88 \%$ \\
\hline $10000+$ & 9 & $7,44 \%$ \\
\hline \multicolumn{2}{r|}{} & $100,00 \%$ \\
\cline { 3 - 3 }
\end{tabular}

As most respondents completed this questionnaire very shortly after the September 11th attacks on the World Trade Centre towers in New York, disaster recovery was a highly topical issue, and security and control has also increased in importance. Decision and Executive Support and Business Intelligence, surprisingly high in the 1999 study, is now ranked as the top issue. The emergence of Customer Relationship Management (CRM) as a top ten IS management issue underlies the need to perform these studies on a regular basis, as this issue was not included in 1999. A major issue highlighted in 1999 was that of recruiting and maintaining IS personnel, which has now slipped down ten places. Unsurprisingly it appears that IS managers are disillusioned with the use of business to consumer eCommerce. Ranked at number four in 1999, it has dropped to number 27. The general tendency was for Internal Effectiveness (IE) issues to increase in importance, and for business relationship (BR) issues to cluster in the lower end of the top ten. Many of the technology application (TA) issues were not listed in 1999, and thus analysis based on these comparisons is limited. Two of the three
Technology Infrastructure (TI) issues rose seven places since 1999, indicating the importance of flexible, well architected systems.

Respondents had the option of adding up to 5 issues they considered relevant. Twenty separate issues were identified, the most popular being on the theme of 'Improving user involvement and ownership', added by 10 respondents. None of these garnered sufficient votes to be significant, but they could be taken into account in future lists.

\section{Objective 2. Comparison of South African Results from 1999 and 2001}

To test for the null hypothesis of no correlation between the 1999 and 2001 results, Spearman rank correlation was used to compare the mean results of the 22 issues common to both studies. The Spearman's Rho of 0,6523 rejects Ho at the $1 \%$ level $(\mathrm{p}=0,001<0,01)$, indicating relatively strong correlation between the results of the South African study by Hall et al. (1999) and of this study. 
Table 2: 2001 Ranked key issues

\begin{tabular}{|c|c|c|c|c|c|}
\hline $\begin{array}{l}2001 \\
\text { Rank }\end{array}$ & Issue & Category & Mean & Std Dev & $\begin{array}{r}1999 \\
\text { Rank }\end{array}$ \\
\hline 1 & Decision and Executive Support and Business Intelligence & TA & 8,07 & 1,8427 & 3 \\
\hline 2 & Building a responsive IT Infrastructure & TI & 8,04 & 1,7146 & 9 \\
\hline 3 & Disaster Recovery & IE & 7,98 & 1,7888 & 8 \\
\hline 4 & Security and control & IE & 7,80 & 2,0560 & 7 \\
\hline 5 & Aligning the IS organisation within the enterprise & $\mathrm{BR}$ & 7,80 & 2,2234 & 2 \\
\hline 6 & Using IS for competitive advantage & $\mathrm{BR}$ & 7,79 & 1,7426 & 1 \\
\hline 7 & Improving IS Strategic Planning & $\mathrm{BR}$ & 7,60 & 1,8911 & 10 \\
\hline 8 & Making effective use of the data resource & $\mathrm{BR}$ & 7,51 & 1,7847 & 11 \\
\hline 9 & Facilitating Organisational Learning & $\mathrm{BR}$ & 7,48 & 1,9498 & 15 \\
\hline 10 & Customer Relationship Management & $\mathrm{BR}$ & 7,48 & 2,1529 & N/A \\
\hline 11 & Developing and Implementing an Information Architecture & TI & 7,26 & 2,3293 & 18 \\
\hline 12 & Measuring IS effectiveness and Productivity & IE & 7,19 & 2,1226 & 16 \\
\hline 13 & Developing and Training IS human resources & IE & 7,13 & 2,0934 & 14 \\
\hline 14 & Planning and managing communication networks & TI & 7,05 & 1,9098 & 13 \\
\hline 15 & Recruiting and Maintaining IS personnel & IE & 7,00 & 2,0083 & 5 \\
\hline 16 & Knowledge Management & IE & 6,99 & 2,1389 & N/A \\
\hline 17 & Increasing the understanding of IS's role and contribution & BR & 6,86 & 2,3815 & 12 \\
\hline 18 & Using Business to Business (B2B) eCommerce & $\mathrm{BR}$ & 6,82 & 2,3094 & N/A \\
\hline 19 & Implementing and Managing Collaborative support systems & TA & 6,77 & 1,9696 & 23 \\
\hline 20 & Managing software development & IE & 6,67 & 2,2781 & 20 \\
\hline 21 & Facilitating and managing end user computing & TA & 6,59 & 2,1003 & 21 \\
\hline 22 & Developing Distributed Systems and (ERP) Systems & TA & 6,53 & 2,2879 & N/A \\
\hline 23 & The business value of Mobile Technology & TA & 6,41 & 2,2645 & N/A \\
\hline 24 & Outsourcing Selected information Services and Systems & IE & 6,41 & 2,4956 & 22 \\
\hline 25 & Object Orientated and Component Based Technologies & TA & 6,16 & 2,4359 & 26 \\
\hline 26 & Managing the existing portfolio of legacy applications & IE & 6,02 & 2,3979 & 28 \\
\hline 27 & Using Business to Consumer eCommerce & TA & 5,90 & 2,4846 & 4 \\
\hline 28 & Application Service Providing (ASP) & IE & 5,73 & 2,4833 & N/A \\
\hline
\end{tabular}

Table 3: Comparison of ranking methods

\begin{tabular}{c|c|c}
\hline Category & $\begin{array}{c}\text { Mean Inverted Ranking } \\
\text { (All Issues) }\end{array}$ & $\begin{array}{c}\text { Weighted Average } \\
\text { (Top 10 Issues) }\end{array}$ \\
\hline BR & 2nd & 1st \\
\hline IE & 3rd & 3rd \\
\hline TI & 1st & 2nd \\
\hline TA & 4th \\
\hline
\end{tabular}

This could be attributed to two years being a very short time-period for issues to change. Added to this, only the issues common to both studies (22 out of 28) were included. This may tend to 'force' the correlation between the studies. As the 1999 sample was relatively small, not too much should be read into this result.

\section{Objective 3. Comparing local and international results}

Compared to the 1997 Australian study (Pervan, 1998)

The means of the 19 issues common to both studies were compared, and a Spearman's Rho of 0,5371 was calculated. Ho can therefore be rejected at the $5 \%$ level $(p=0,0177<0,05)$, and a conclusion drawn that there is significant correlation between the results of the 1997 Australian study by Pervan (1998) and the results of this study. This is interesting, as according to Palvia et al. (2002), Australia is categorised as an 'Advanced' country. If judged according to the same criteria, that is GDP per capita, then South Africa with a GDP of \$8,500 (The World Factbook, 2001), would be a 'Newly Industrialized' country. One might not expect the issues faced by the two countries to be as similar as the correlation suggests.

There are, however, a number of other contributing factors. The Australian study was done four years previously, and issues faced then may only now become important in South 
Africa. As only 19 issues are compared between the two studies, the results may be skewed towards issues that have become standard in IS for the last few years. In addition, the Australian study sought the views of CEO's.

Compared to the 1995 USA's SIM study (Brancheau et al., 1996)

The same procedure used in the Australian comparison above, was applied to the 20 issues common to the USA study and this study. The Spearman's Rho of 0,2761 is not significant at the $5 \%$ or even $20 \%$ level $(\mathrm{p}=0,2385>0,2)$, and thus the null hypothesis cannot be rejected. It appears that the issues seen as important 7 years previously in the USA were not important in South Africa in 2001. Picton (1989) proposed that South Africa followed the trends of developed countries by about 5 years, but Hall et al. (1999) concluded that this was no longer the case. From the 2001 results either the latter proposition is supported, or South African issues are becoming more aligned with those of developed countries. Objective 5 will try to uncover any relationship between issues faced by a country and its economic status.

\section{Objective 4: Test if the category split of issues is associated with:}

Position, Location, Industry Sector, Organisation Size, or Geographical Reach

To test the above, null and alternative hypotheses were constructed for each of the five variables. The null hypotheses were of the form: ' $\mathrm{H}_{0}$ : There is no association between the ratings of the different categories of issues and the variable under consideration.' The Issue category gaining the highest average score was determined for each respondent, and the proportions of BR, IE, TA and TI compared against demographics. The Chi-squared statistic was used, grouping categories of the variables if necessary to avoid test invalidity due to low expected values. Results are summarised in Table 4. This shows that none of the null hypotheses can be rejected at a $5 \%$ level.

The lack of association was fairly surprising, and so correspondence analysis was also carried out for each demographic variable, giving a graphic representation of associations (largely the lack of them). It did not contradict the chi-squared results overall for any of the demographics. Certain moderate relationships for some subgroups were however suggested, sometimes only in the first dimension of the correspondence analysis plot. There is not room to discuss these here. Finally, to assess the impact of including non-IS managers in the sample, a Spearman rank correlation was calculated for the mean issue ratings of IS managers versus non-IS managers. The Spearman Rho of 0,8635 has an associated p-level of $<0,000001$, showing very high correlation between their rankings. Overall this showed that any imbalance in the sample composition did not have a significant influence on the main results of the study. It should however be noted that certain smaller geographic regions were absent from the sample.

\section{Objective 5. Determine whether a country's economic status has an effect on its key IS management issues.}

Watson et al. (1997) suggested that key issues studies need to progress from only listing and commenting on the top issues, to increasing understanding of what makes an issue prominent. It was therefore decided to investigate whether or not issues were indicative of the economic status of the country in which they were obtained. Single linkage cluster analysis was performed using the mean score for each of the four categories as the differentiating variable. The six countries chosen had conducted recent studies into key issues using the SIM approach, and so were comparable.

Figure 3 shows that three separate clusters were identified: Cluster 1 - Guatemala and Costa Rica; Cluster 2 - Canada and Australia; Cluster 3 - South Africa and Indonesia.

Palvia et al.'s (2002) model of classification is based on GDP per capita. If this is extended to include countries from the above list not in their study, the following groups are arrived at (Palvia et al., 2002; Pook \& Pence, 2001; U.S. Department of State, 1997):

- Advanced: Australia $(\$ 18,500)$, Canada $(\$ 20,970)$

- $\quad$ Newly Industrialised:South Africa $(\$ 8,500)$

- Developing:Costa Rica $(\$ 2,964)$, Guatemala $(\$ 1,366)$, Indonesia $(\$ 1,013)$.

The cluster analysis performed on the basis of key issues ranking found the same clusters/groups as those in Palvia et al.'s (2002) paper using only financial information. In addition, Pook and Pence (2001) also found the same clusters, using three different dimensions (Technology, Information Infrastructure and Social Indicators). In this analysis, only Indonesia was not classified in the corresponding group. (Further examination of the Indonesian study revealed that it was not comprehensive, with only 28 respondents). This suggests an association between the economic status of a country and the issues faced by it, and the need for global differences to be given greater consideration in the development of future questionnaires and analysis.

\section{Objective 6. Determine whether the four category classification model used is appropriate in the South African context.}

Most previous studies have used the Niederman et al. (1991) classification as the basis for comparison between studies. No standard statistical procedure has however been used in these studies when new issues are added to the questionnaire, and the placement of new issues under the different categories can be fairly subjective. If the existing classification scheme is appropriate, factor analysis should group the issues into four factors, and these factors should have the correct issues associated with them. A factor analysis carried out on the 2001 SA data gave the following results: 


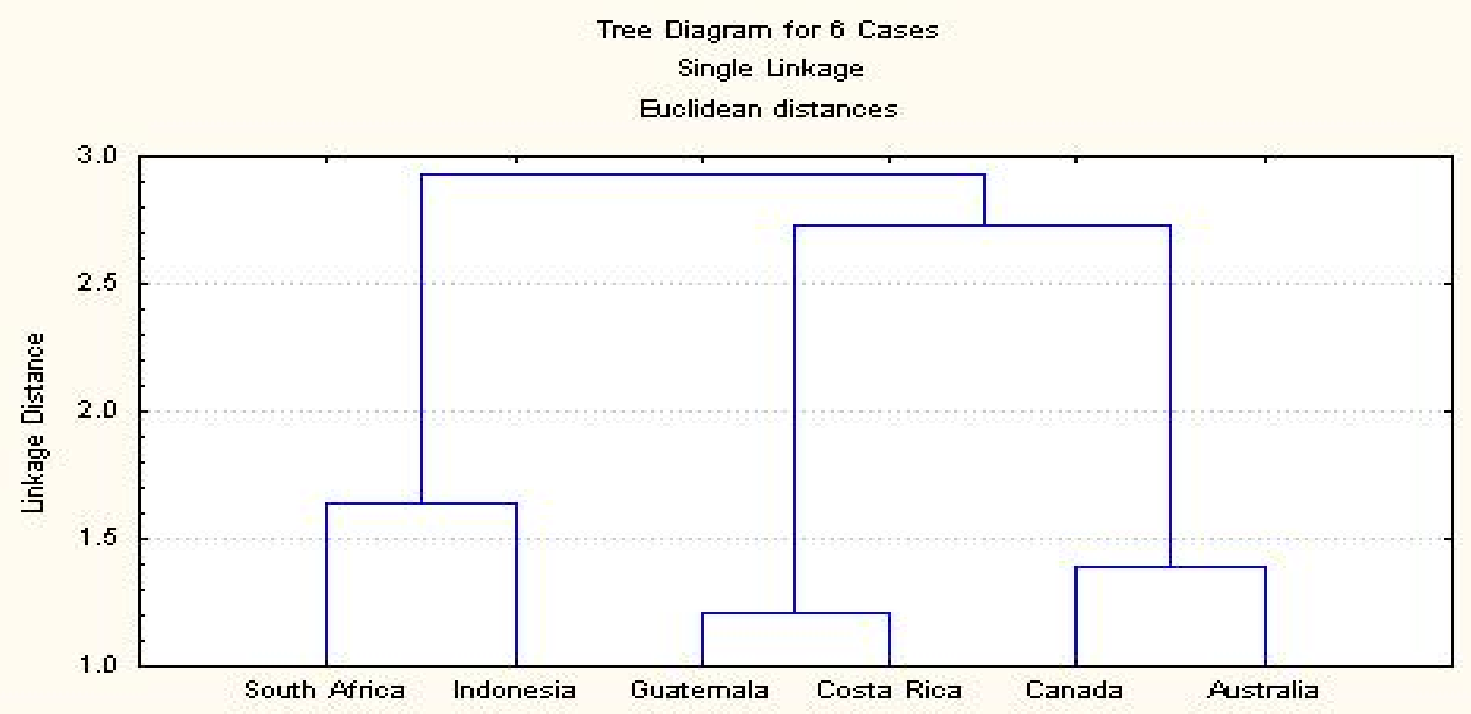

Figure 3: Cluster analysis - countries' economic status

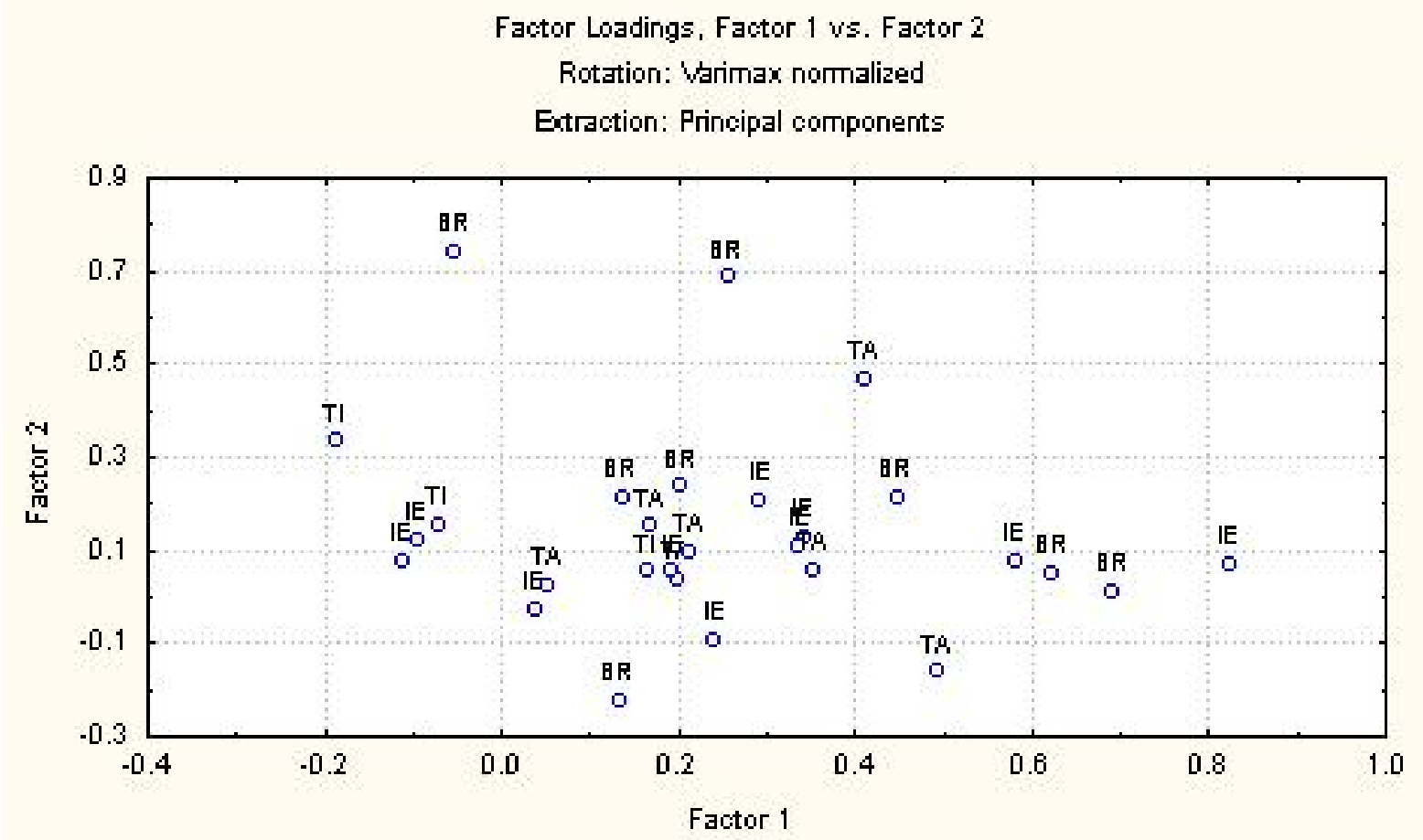

Figure 4: Factor analysis - classification model

Table 4: Summary of Chi- squared tests for possible influences

\begin{tabular}{c|c|c}
\hline Demographic & Chi-squared & P-level \\
\hline Position & 1,673 & 0,643 \\
\hline Location & 5,614 & 0,934 \\
\hline Industry Sector & 7,555 & 0,109 \\
\hline Organisation Size & 3,646 & 0,724 \\
\hline Organisational Geographical Reach & 2,124 & 0,908 \\
\hline
\end{tabular}

- $\quad$ Nine significant factors were extracted using the Kaiser Criterion, (i.e. with eigenvalues $>=1$ ). Factors 1 and 2 explained the most variation (28,23\% and $7,26 \%$ respectively) and are shown in Figure 4.

- Only 12 issues had factor loadings $>0,7$. At most two issues with loadings of this order were associated with each factor.

This analysis suggests that the Niederman et al. (1991) classification model does not suitably categorise the local issues. Results obtained are very similar to those of Palvia and Basu (1999), using the Niederman et al. (1991) data. They found ten factors, with only 9 out of 20 factor loadings $>0,7$. From the results obtained here it appears that there is no clear and reliable grouping of the issues (even into 9 factors). Cluster analysis was also performed, but this did not find any distinctive or practical groupings of issues 
either. This highlights the difficulty of allocating a new issue to an existing category.

\section{Conclusions and recommendations}

Business Relationship (BR) issues dominate the lower end of the top ten, while 'Decision and executive support and business intelligence', a Technology Application (TA) received the highest rating (Objective 1). This research was done within weeks of the September $11^{\text {th }}$ attack on the World Trade Centre, which may have contributed to 'Disaster recovery' and 'Security and control', both Internal Effectiveness (IE) issues, being ranked in the top 4. There was significant correlation between the 2001 issues and those of the 1999 South African study (Objective 2) and a 1997 Australian survey (Objective 3), but not with the 1995 USA study, due to the combination of large regional and time differences.

The local demographic factors measured were not shown to have a significant impact on the overall ratings of issues (Objective 4), although other methods of analysis can still be attempted. It should again be stressed that, due to the over-representation of the Western Cape in the sample, it may be inappropriate to regard these results as representative of all regions of South Africa. Key management issues were shown to be associated with the country's economic status (Objective 5). Developing, advanced and newly industrialised countries have faced the same key IS management issues at similar times in their development, and classification models should try to include regional factors. The four category classification model for issues (BR, IE, TA and TI) is subjective, and does not correctly classify all the issues in this study (Objective 6).

Given the political, military and economic events of the past few years, increased awareness of security and corporate governance, and the changed fortunes of the IT industry and marketplace, it is most important to repeat similar studies regularly. A comprehensive sample of local IS managers and CIO's needs to be developed and targeted. Further research should be done to determine the relationship between studies at different times and places. The existing classification method should be further investigated, possibly using multi-discriminant analysis, and adapted to suitably classify new issues, and take into account regional effects. This should be compatible with the large number of studies already completed so that new research can add usefully to the body of knowledge, and assist local IS managers with their decision making.

\section{References}

Ball, L. \& Harris, R. 1982. 'SMIS members: A membership analysis’, MIS Quarterly, 6(1):19-38.

Brancheau, J.C., Janz B.D. \& Wetherbe, J.C. 1996. 'Key issues in information systems management', MIS Quarterly, 20(2):225-242.

Brancheau, J.C. \& Wetherbe, J.C. 1987. 'Key issues in information systems management', MIS Quarterly, 11(1):23-45.
Chou, H-W. \& Jou, S-B. 1999. 'MIS key issues in Taiwan's enterprises', International Journal of Information Management, 19:369-387.

Dekleva, S. \& Zupancic, J. 1996. 'Key issues in information systems management: A Delphi study in Slovenia', Information \& Management, 31:1-11.

Dickson, G.W., Leitheiser, R.L., Nechis, M. \& Wetherbe, J.C. 1984. 'Key information systems issues for the 1980s', MIS Quarterly, 8(3):135-148.

Ein-Dor, P., Myers, M. \& Raman, K.S. 1997. 'Information technology in three small developed countries', Journal of MIS, 13(4):61-89.

Gibson, J., Donnelly, J. \& Ivancevich, J. 2000. Organisations. Boston, Mass: Irwin McGraw-Hill.

Gottschalk, G. 1998. 'Global comparison of key issues in IS management: Extending initial selection procedure and an empirical study in Norway', Journal of Global Information Technology Management, 2(4):41-60.

Gottschalk, P., Watson, R.T. \& Christensen, B.H. 2000. 'Global comparisons of key issues in IS management: Extending key issues selection procedure and survey Approach'. Proceedings of the 33rd Hawaii International Conference on System Sciences (HICSS-33), Maui, USA.

Hall, J., Hartley, R., Mkhasibe, J. \& Hart, M. 1999. 'Key issues in managing information systems in South Africa in 1999.' Empirical Research Report, Department of Information Systems, University of Cape Town.

Hart, M. 2000. 'What information management topics should we teach?' In Stander, A. (Ed.). Proceedings of the Annual Conference of the South African Computer Lecturers Association (SACLA 2000). Cape Town: SACLA, pp. 96104.

Hodge, J. \& Miller, J. 1997. 'Information technology in South Africa: The state-of-the-art and implications for national IT policy'. Working Paper No 3, Development Policy Research Unit, University of Cape Town.

IDC. 2001. eWorld 2001. [online] URL http://www.idc.com:8080/ITOver/eworld htm). Accessed $1 / 5 / 2001$.

Mata, F.J. \& Fuerst, W.L. 1997. 'Information systems management issues in central America: A multinational and comparative study', Journal of Strategic Information Systems, 6:173-202.

Niederman, F., Brancheau, J. \& Wetherbe J. 1991. 'Information systems management issues for the 1990s', MIS Quarterly, 15(4):474-500.

Palvia, P.C. \& Basu, S.C. 1999. 'Information systems management issues: Reporting and relevance', Decision Sciences, 30(1):273-290. 
Palvia, P.C., Palvia, S.C. \& Whitworth, J.E. 2002. 'Global information technology: A meta analysis of key issues', Information \& Management, 39(5):403-414.

Palvia, P.C., Palvia, S.C. \& Zigli, R.M. 1992. The global issues of information technology management. Hershey, Pennsylvania: Idea Group Publishing.

Pervan, G. 1998. 'How chief executive officers in large organisations view the management of their information systems', Journal of Information Technology, 17(2):95-109.

Picton, J. 1989. 'Key information systems management issues in South Africa', Technical Report, Department of Information Systems, University of Cape Town.

Pook, L.A. \& Pence, N. 2001. 'Relationship between technology and social development: A worldwide assessment with conclusions for Eastern Europe'. In Harriger, A. (Ed.). Proceedings of the Annual Informing Science Conference, Krakow, Poland, pp. 415-424.

PricewaterhouseCoopers. 2001. Barometer Surveys: January 2001.

[Online]URL:http://www.barometersurveys.com/pr/te01040 $4 \mathrm{html}$. Accessed 30/4/2001.

Remenyi, D., Lubbe, S., Meiring, F. \& Smith, B. 1999. 'Some information systems issues in South Africa and suggestions as to how to deal with them in the new millennium'. [Online] URL:

http://www.cs.wits.ac.za/ philip/SAICSIT/SAICSIT99/papers exp html. Accessed 1/10/2001.

Remenyi, D. \& Whittaker, L. 1995. 'Management of information technology in South Africa: Initiatives in the mid-1990s', South African Journal of Business Management, 26(4):144-151.

Rockart, J.F., Earl, M.J. \& Ross, J.W. 1996. 'Eight imperatives for the new IT organisation', Sloan Management Review, 38(1):43-55.

SAITIS. 2000. 'South African ICT Sector Development Framework’ [Online] URL: http://www.saitis.co.za. Accessed 11/10/2001.

The World Factbook. South Africa. 2001. [Online] URL: http://www.cia.gov/cia/publications/factbook/index html. Accessed 14/11/2001.

U.S. Department of State. 1997. Country Profile. [Online] URL:

http://www.state.gov/www/regions/wha/cp costa rica 0497 html. Accessed 14/10/2001.

Watson, R.T. \& Brancheau, J. 1991. 'Key issues in information systems management: An international perspective', Information \& Management, 20(3):213-223.

Watson, R.T., Kelly, G.G., Galliers, R.D. \& Brancheau, J.C. 1997. 'Key issues in information systems management: An international perspective', Journal of Management Information Systems, 13:91-115. 
